\title{
Spat over firing threatens medical school at US-Mexico border
}

Texas Tech University's fledgling medical school in El Paso is floundering after the university's firing of the school's founding dean, Robert Suskind, in September.

The upheaval could impact the new school's accreditation by the Liaison Committee on Medical Education, which is jointly sponsored by the American Medical Association and the Association of American Medical Colleges.

Barbara Barzansky, a representative of the American Medical Association, says administrative turnover is not in itself a problem. "What the [accreditation committee] looks for is stability of purpose," she says. "Is the school still moving or has the administrative turnover created such a stumbling block that all progress has stopped?"

Texas Tech, which is based in Lubbock, has operated a campus of its Health Sciences Center in El Paso, with a regional medical school that trains third- and fourth-year medical students and residents, for more than 30 years.

In October 2006, Texas Tech hired Suskind, who was then dean of the Chicago Medical School at Rosalind Franklin University of Medicine and Science, to transform the regional campus into an accredited four-year program.

The school is of particular interest because it is located in a growing community near the Mexican border, where the ratio of physicians to patients is among the lowest in the country. "Other than placing it 50 miles inside of Mexico," says rural medicine expert Robert Bowman at the University of Nebraska Medical Center in Omaha, "you couldn't ask for a better place."

Under Suskind's leadership, the school secured \$43 million from the Texas legislature

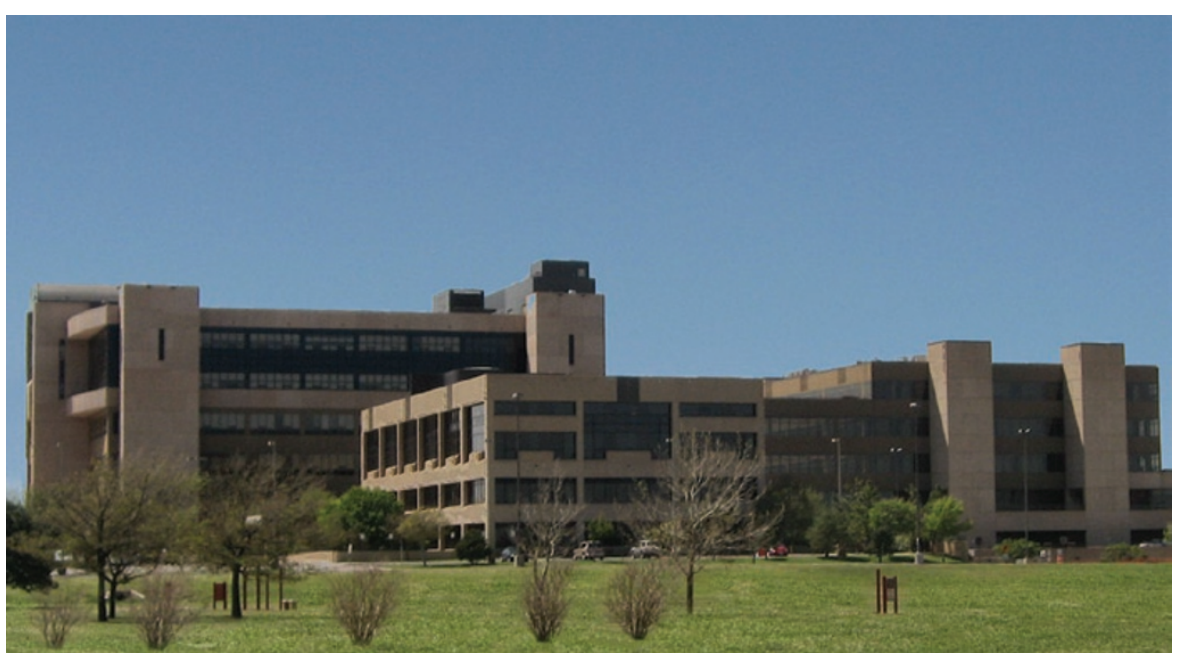

Texas Tech's campus.

and another $\$ 50$ million from oil refinery owner Paul Foster, after whom the school is now named.

But Suskind may not have been in touch with the local community's needs. He built a program with a research emphasis on cancer, obesity and diabetes, infectious diseases and neurodegenerative diseases. "When I came and spoke, I told them exactly what I wanted to do," says Suskind, who says he is furious with the university's action. "If they decided they didn't want that, they should have never asked me to come down," he says.

The accreditation committee was set to visit the new school on 11 November. But in the runup to the committee's visit, John Baldwin, who took over as the Health Science Center's new president in August, asked Suskind to resign. When Suskind refused, he was fired.

"I think 'surprise' is the best word," to describe the medical school faculty's reaction, says Henry Mandin, a visiting professor from the University of Calgary who helped Suskind design the curriculum.

Baldwin did not respond to repeated requests for interviews from Nature Medicine. But according to an article in the El Paso Times, he was opposed to Suskind's focus on research. In late September, Baldwin reinstated Jose Manuel de la Rosa, who had served as regional dean for more than a decade before Suskind replaced him. De la Rosa promptly placed the administrative team Suskind had put together on a 90-day probation.

Former interim president of Texas Tech's Health Sciences Center, Bernard Mittemeyerwith whom Suskind says he had a good working relationship—says he was frustrated by many of

$$
\text { was }
$$
we amicable. He later moved on to Chicago. Still, his energy, enthusiasm and recruiting skills have won him many admirers. "It is impossible not to like Bob Suskind," says Ricardo Sorenson, a pediatrician who came to LSU thanks to Suskind's recruiting efforts and succeeded him there as department chair.

In the meantime, Texas Tech's accreditation visit happened as planned, and the committee will make its final decision in February 2008. In a guest editorial published in the El Paso Times on 7 October, de la Rosa said he would guide the school through the process by focusing on recruiting teaching faculty. "We are just about 23 months from realizing our greatest dreamseating the first class of four-year medical school students," he wrote.

Brendan Borrell, New York 